\title{
An Open Model for Researching the Role of Culture in Online Self-Disclosure
}

\author{
Christine Bauer \\ Johannes Kepler University Linz \\ christine.bauer@jku.at
}

\author{
Katharina Sophie Schmid \\ University of Vienna \\ katharina.sophie.schmid@gmail.com
}

\author{
Christine Strauss \\ University of Vienna \\ christine.strauss@univie.ac.at
}

\begin{abstract}
The analysis of consumers' personal information (PI) is a significant source to learn about consumers. In online settings, many consumers disclose PI abundantly - this is particularly true for information provided on social network services. Still, people manage the privacy level they want to maintain by disclosing by disclosing PI accordingly. In addition, studies have shown that consumers' online selfdisclosure (OSD) differs across cultures. Therefore, intelligent systems should consider cultural issues when collecting, processing, storing or protecting data from consumers. However, existing studies typically rely on a comparison of two cultures, providing valuable insights but not drawing a comprehensive picture.

We introduce an open research model for cultural OSD research, based on the privacy calculus theory. Our open research model incorporates six cultural dimensions, six predictors, and 24 structured propositions. It represents a comprehensive approach that provides a basis to explain possible cultural OSD phenomena in a systematic way.
\end{abstract}

\section{Introduction}

Organizations are entering an era where real time data is available about their operations and their environments, offering new opportunities to increase their performance as well as enhanced chances to meet their customers' demands. Collecting data is no longer limited to an organization's internal processes or to its internal information flows: in fact, data is available about almost any aspect of its business. The key challenge for a successful enterprise is to transform information systems into intelligent systems that are able to manage the abundance of data and that are in accordance with the stakeholders' requirements and preferences.

A major source to learn about consumers is the personal information (PI) that they disclose about themselves. In fact, in electronic business-to-consumer relations, organizations typically require users to disclose PI, such as credentials for authentication, e.g. [34], contact and payment details for invoicing and payment for online purchases, e.g. [51], or information on the user's preferences for personalized recommender systems, e.g. [3], as well as personalized advertising, e.g. [9]. Moreover, many types of content that users generate on the Web (i.e. user-generated content) is PI that individuals disclose; for instance, textual postings and comments on online social networks or visual information such as photos or videos on respective platforms $[18,46]$. Social network services (SNSs) such as Facebook or YouTube would be nonexistent without having users disclosing PI [73] as providers of such services build their entire business on users' online self-disclosure (OSD). In short: OSD is a highly valuable source of information to sustain an organization's market position (e.g. for innovations, customization, marketing strategies, etc.). Consequently, the phenomenon of OSD has become an increasingly researched topic in various research threads such as information systems, e.g. [78], media psychology, e.g. [66], ethics, e.g. [26], or business economics, e.g. [31].

Still, it is not always favorable for users to provide PI openly. In fact, disclosing too much PI may have negative implications [2,4,39], including fraud, identity theft, violation of privacy rights, security attacks, or cyber-stalking $[4,39,55,58]$. As a consequence, people attempt "to manage the level of privacy that they wish to maintain" [67]. The so-called "privacy calculus theory" [23] has repeatedly been acknowledged as a suitable framework for studying OSD, e.g. [43]. This theory puts forth four determinants of OSD (i.e. anticipation of benefits, privacy concerns, trusting beliefs, and risk beliefs), which individuals weigh against each other and decide whether or not (and/or how much) to disclose [23].

The framework of "privacy as contextual integrity" $[56,57]$ suggests that individuals adhere to norms that govern what is considered appropriate to reveal in which context. Since norms vary across groups, OSD behavior rendered appropriate or inappropriate is also likely to be differently manifested in norms. 
Fundamentally, the conception of privacy (which represents the substantial basis of the privacy calculus theory explaining OSD) varies from culture to culture $[26,56]$. Culturally-determined attitudes or beliefs may affect the user's decision whether or not to disclose PI.

However, most OSD studies either consider and analyze OSD on a worldwide uniform basis, e.g. [10], or study one-country samples without deeper cultural consideration, e.g. [40]. Still, several studies have shown that OSD differs across cultures, e.g. [11,41,62].

This culture-driven heterogeneity and its effects need to be analyzed in order to develop appropriate approaches to exploit but also to protect the users' PI. If disclosed PI differs across cultures, then the provided PI has different levels of breadth, depth, and validity. Furthermore, uniform interaction patterns with users will result in different degrees of OSD in various cultures. In this context, it seems important to note that organizations need to comply with privacy regulations (e.g. the Regulation (EU) 2016/679 of the European Parliament and of the Council of 27 April 2016 on the protection of natural persons with regard to the processing of personal data and on the free movement of such data [63]) when it comes to the exploitation of PI. In addition, corporate social responsibility implies responsible handling of PI $[8,14]$. Still, specific mechanisms and purposive activities may be necessary in initiatives for engaging in responsible and social actions to prevent individuals from disclosing "too much PI". In short, organizations need to adapt their strategies when using/exploiting PI from different countries.

In the context of OSD, Krasnova, et al. [43] provide significant insights into the role of culture; they investigate the effect of two out of Hofstede's six cultural dimensions [32,33]. Still, Bauer and Schiffinger [11] indicate that especially the prominently investigated individualism dimension is "quite far from being the most important culturerelated moderator of OSD". They call for a research framework that allows for a bigger picture on the role of culture in the context of OSD.

Calling on this research gap, the present paper introduces an open research model for researching the role of culture in OSD, based on the privacy calculus theory [23] and the cultural dimensions by Hofstede $[32,33]$. We use the term "open research model" for the following reasons: $(i)$ the model is open as we do not and cannot claim that the research model is exhaustive, as further influencing factors may be considered; (ii) it is a model and not a framework because we identify various impacts of predictormoderator-effects; (iii) it is a research model and not a technical model because we formulate propositions (and do not describe a technical structure).
Research on the role of culture in online selfdisclosure on a worldwide basis across various cultures is highly complex and requires a large set of extensive empirical studies. Accordingly, a consistent research model is significant to warrant homogeneity such that empirical results of different research teams with samples of different cultures will be valid and comparable. Our proposed open model provides such a basis.

The remainder of this paper is structured as follows: Section 2 provides the conceptual background of our research. We describe the concept of OSD, its predictors, and the impact of cultural dimensions on OSD. In Section 3, we develop 24 structured propositions based on findings from prior research. The literature basis builds on the ones provided in the meta-analyses by Bauer and Schiffinger $[10,11]$ and was supplemented by targeted search for cultural aspects in OSD. The final section discusses and highlights our work's implications for further research and its practical use.

\section{Background and Related Work}

\subsection{Online Self-Disclosure}

Self-disclosure (SD) is defined as the communication of previously unknown personal, private information to others $[17,37]$. This may include facts about oneself, own experiences, or thoughts and feelings [17]. SD is an essential part of human communication (e.g. for forming and maintaining personal relationships), but also for validation of opinions, values, and perceptions $[21,65]$. It is generally regarded a risky act due to the intimacy of PI, which can lead to ridicule and rejection. This in turn can leave the discloser feeling awkward and vulnerable [60].

SD occurring online is referred to as online selfdisclosure (OSD). Several studies have found that computer-mediated communication such as emailing and instant messaging exhibits different patterns of SD than, for instance, face-to-face (f2f) interactions. This is due to various factors such as anonymity, reduced non-verbal cues and more control over time and pace $[48,72]$. SD plays an important role in various fields of computer-mediated communication. It is used to establish legitimacy in SNSs, to reduce uncertainty experienced by others about oneself, or as a qualification for online services and transactions [28]. In an SNS context, SD refers to personal details, news, beliefs or even ideas shared on an online platform [43]. 


\subsection{Predictors of Online Self-Disclosure}

Various models have been used to explain OSD. Social exchange theory, for example, explains that individuals assess the costs and benefits of engaging in relationships. A relationship is considered worthy of engaging in, once perceived benefits outweigh associated costs [38]. Social penetration theory extends this view by taking into consideration the amount and nature of costs and benefits involved in SD. Among those are reciprocation (i.e. disclosing PI as a response to someone else's SD [7]) and vulnerability. Again, individuals analyze the risks and benefits involved and engage in SD if the assumed balance is positive for them [5].

Privacy calculus theory defines four determinants of a person's OSD: anticipation of benefits, privacy concerns, trusting beliefs, and risk beliefs. Its basic premise is that individuals assess the overall risk of engaging in OSD while taking anticipated benefits into consideration [23]. This model has been extensively used to examine OSD behavior in individuals [43].

Anticipated benefits refer to the rewards an individual expects to obtain as a result of disclosing PI. Among such rewards are enjoyment, social acceptance, and self-presentation $[13,69]$. Privacy concerns imply the fear of losing privacy after disclosing PI [79]. This can occur in an OSD context when another party is acting opportunistically. Trusting beliefs, on the other hand, relate to individuals trusting that their PI will be handled in a competent, reliable, responsible and safe manner. Lastly, risk beliefs refer to an individual's perception and awareness of opportunistic behavior of others, that might cause negative effects for the individual [23].

Additional factors derived from social exchange theory and social penetration theory affecting OSD such as perceived anonymity and perceived reciprocity have gained substantial attention in research as well [62]. Therefore, they will also be included into our research model; as a result, we incorporate six predictors in our open model, i.e. anticipated benefits, trusting beliefs, privacy concerns, risk beliefs, perceived anonymity, and perceived reciprocity.

\subsection{Online Self-Disclosure in Different Cultural Contexts}

The construct "contextual integrity" [56,57] ties protection for privacy to norms of specific contexts. What counts as private and what is considered appropriate to be revealed in a certain context may vary across cultures, as norms vary across cultures [56].
While OSD is mainly researched in a worldwide context (e.g. by studying a sample of Facebook users), it has also been subject to studies in a particular cultural context; for instance, investigating a Russian sample, e.g. [40] or one from Germany, e.g. [68].

Other studies compare two countries. For example, a survey interviewing Moroccan and US-American Facebook users revealed that Moroccans generally disclose less PI than Americans, as they perceive the damage incurred in case of violation as higher. Americans, in turn, showed lower privacy concerns than Moroccans [77]. Similar results were found regarding perceptions and behavior of Americans [41]. Overall, Americans were more involved in Facebook, felt more in control over sharing PI, and had greater trust in the SNS than Germans, who had less trust in the provider and felt less in control of how their PI was being handled. Another study using American and German participants also found that trust was a major determinant of SD decisions of Americans, while German participants based their decisions on privacy concerns [42]. By contrast, a survey conducted both f2f and online with American and Chinese participants showed that Americans anticipated more SD in f2f interactions than in online settings. A major source of concern was for Americans to have other members of their online community find out about their PI, whereas the Chinese participants were more concerned about third-party access to their PI from f2f communication [80]. In addition, some differences regarding user goals, self-expression, and interaction behavior online between different cultures were revealed [16].

However, studies dealing with SNSs and the role of culture have mostly focused on industrialized countries, e.g. $[42,80]$. Additionally, studies examining OSD have largely utilized small samples from certain segments such as university students, e.g. $[25,27]$. Moreover, the data used by these studies was mostly based on self-reporting instead of being behavioral in nature [40]. However, the scarce existing research has found that online interaction is indeed not culturally neutral $[11,25,61,68]$.

\subsection{The Impact of Culture on Online Self- Disclosure}

The concept of culture is a very broad one, which is associated with local values, beliefs and traditions [32]. The arguably most frequently cited and widely accepted typology to differentiate between cultures has been presented by Hofstede [32,33]. His framework is based on data gathered from 116,000 IBM employees from over 70 different countries, which he collected between 1967 and 1973 [32]. Based on his findings, he proposed five distinctive dimensions to describe a 
country's culture, i.e. individualism/collectivism, power distance, uncertainty avoidance, masculinity/femininity, and long-term orientation. A sixth one, namely indulgence, was added later [33]. The scores of each country are not to be considered absolute values but rather as ones relative to other countries' scores. Additionally, they do not describe each individual's characteristics in their respective society but rather collective trends and tendencies [33]. Hofstede's dimensions have been found to not just be applicable in the offline world, but also in online interactions $[45,75]$.

A few studies have explored the effect of culture on OSD and related aspects such as privacy concerns taken from privacy calculus [12,53]. For example, [43] have picked two dimensions from Hofstede's approach (i.e. individualism and uncertainty avoidance) and compared the behaviour of SNS users from the United States and Germany. Moderating effects of these two dimensions on the relation of the privacy calculus concepts and OSD have been analysed in their study and have been identified as pivotal determinants for further research on cultural differentiation, e.g. [30,43]; other dimensions are yet to be explored in research on the influence of culture in the context of OSD (see also [11]).

Overall, we claim that there is a need for a comprehensive research model that supports overcoming the complexity of the cultural impact on OSD. Only a consistent research model may warrant that studies with samples of different cultures, investigated by different research teams, will be valid and comparable. Thus, we substantiate a set of propositions based on extant theories and research in the following Section Error! Reference source not found. and propose an open research model.

\section{Propositions for Research on the Role of Culture in Online Self-Disclosure}

This section outlines the propositions (P1-P12c) concerning the predictors of OSD (Section 3.1) and the moderating influence of culture (Section 3.2). The open research model is visualized in Figure 1.

\subsection{Predictors of Online Self-disclosure}

Online users engaging in SD expect certain benefits from their activities, such as enjoyment or social acceptance $[64,69]$. Self-presentation and relationship maintenance are central benefits and drivers of OSD $[23,41]$. A positive balance of benefits and drawbacks from engaging in online activity favors OSD [23,38].

P1: Anticipated benefits have a positive effect on OSD.
Trust as another important factor in OSD is considered as a precondition for disclosing information [81]. Social exchange theory states that SD is more likely to occur if the relational partner is considered trustworthy [44,71]. This correlation has also been found for trust in online community members [62].

In e-commerce, consumers will most of the time only disclose themselves and thus make a purchase if they perceive a merchant as trustworthy [6]. Moreover, trust plays an important role in online communities where platforms are considered as reliable and trustworthy if PI is treated accordingly [62]. Trust may even out the negative impact of risk beliefs so that trusting parties may engage in risky behavior if a certain level of trust exceeds the level of perceived risk $[23,29]$.

P2: Trusting beliefs have a positive effect on OSD.

Users feel more comfortable disclosing PI if the platform establishes higher levels of privacy among them [76]. Additionally, a study showed that privacy processes differ based on whether they are dispositional or situational [35]. The study also showed that the general privacy disposition has no effect on situation-related interpretation of trustworthiness, and that trust has a moderating effect on perceived privacy. Privacy concerns have also been named as reasons for refusing online transactions [19].

P3: Privacy concerns have a negative effect on OSD. P4: Risk beliefs have a negative effect on OSD.

Studies have shown that the lack of personal identification decreases inhibition, which in turn leads to people sharing more PI than otherwise [20,59]. Also, people tend to disclose more PI in an online environment, as condemnation and rejection may not be attributed to them personally [49]. Thus, anonymity may lead to disinhibition among online users, which in turn makes them more likely to disclose PI.

P5: Perceived anonymity has a positive effect on OSD.

A key aspect of SD is reciprocity. Research has shown that people are much more likely to disclose PI if their communication partner disclosed PI about himself or herself earlier on. Such findings are backed by social penetration theory, according to which a person engaging in social interactions will share more PI in order to maximize perceived benefits [38]. This is also applicable for online interactions such as instant messaging [54]. A study by Posey, et al. [62] revealed that reciprocity had the greatest influence on OSD.

P6: Perceived reciprocity has a positive effect on OSD. 


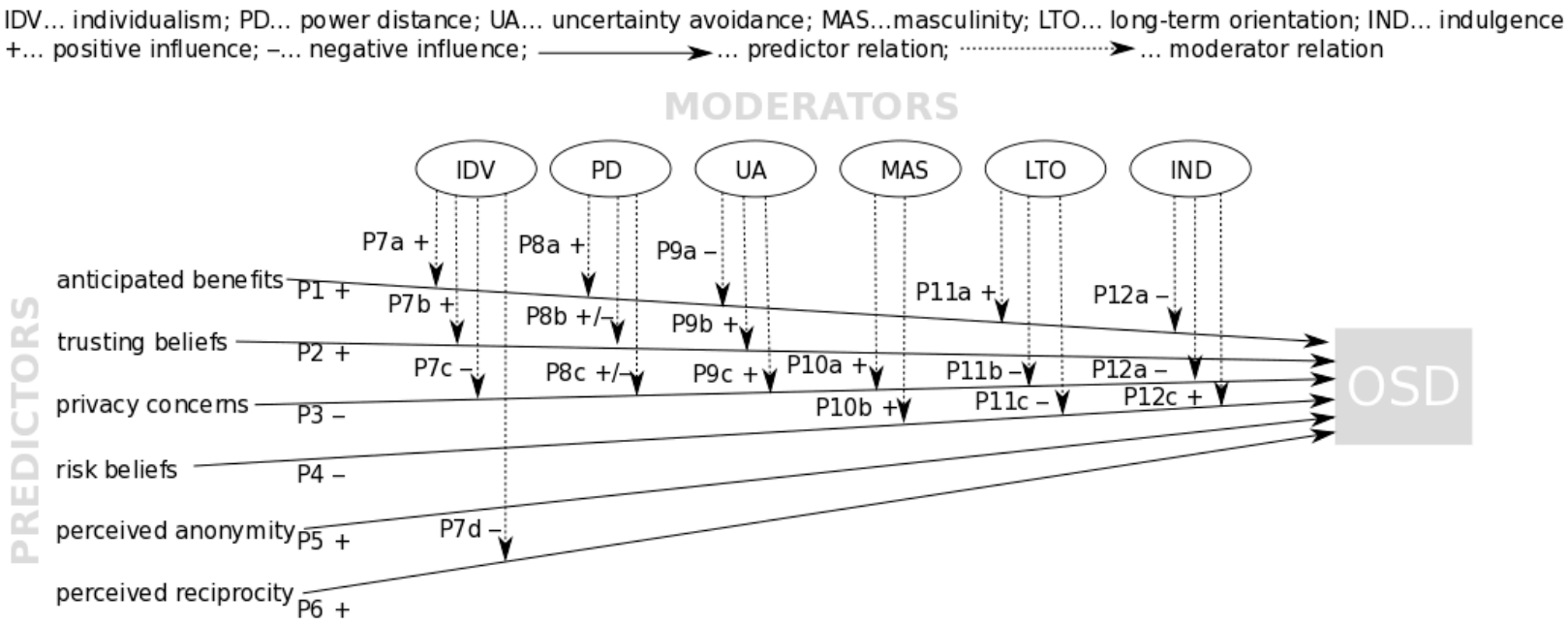

Figure 1. An open model for researching the role of culture in OSD

\subsection{The Moderating Influence of Culture}

Individualism (IDV) refers to a person's independence from collectivity and organizations, and looser ties between them. Collectivism stands for the opposite and implies stronger integration of individuals into groups and organizations [33].

As a consequence, certain traits such as hedonism and pleasure-seeking are attributed to individualistic cultures, where people prioritize their personal needs $[22,74]$. In an online context, it can thus be concluded that the effect of anticipated benefits on $S D$ from engaging in online activities will be enhanced for cultures with higher levels of individualism due to their hedonic traits.

P7a: Individualism increases the positive effect of anticipated benefits on OSD.

The trust-formation process differs substantially between individualistic and collectivistic cultures. Collectivists focus on the predictability of future actions taken by the trustee, as well as his benevolence and the transferability of trust within a group. Individualists, on the other hand, calculate the costs and benefits of their interaction with a trustee [24]. Krasnova and Veltri [42] highlighted these assumptions by revealing that highly individualistic Americans put substantial emphasis on trust in SNS providers when making online decisions.

P7b: Individualism increases the positive effect of trusting beliefs on OSD.

While individualists attribute greater value to privacy, collectivists do not mind intrusion into their private life as much. Research has found that countries with higher levels of individualism also tend to be more concerned about their online privacy $[47,53]$. For example, Dinev, et al. [22] revealed that privacy concerns had greater influence on the use of ecommerce in more individualistic cultures. Paradoxically, it has also been reported that individualists on average share more photos online than collectivists [33]. Based on the abovementioned findings, the following can be stated about the moderating effect of individualism:

P7c: Individualism decreases the negative effect of privacy concerns on OSD.

Furthermore, it has been observed that collectivists are more likely to reciprocate to others than individualists [62]. This could be explained by the fact that collectivists put a stronger emphasis on social interaction in groups than to their personal independence from others [33].

P7d: Individualism decreases the effect of perceived reciprocity on OSD.

Power distance (PD) describes the acceptance of inequality of power in a country. Countries with greater power distance are thus more accepting of power inequality than those with a lower score. However, higher levels of PD have been found to be associated with greater mistrust and privacy concern $[12,52,53]$. Contrary to this, Cao and Everard [15] argued that countries with high levels of PD are less concerned about their privacy since they are used to authorities accessing their PI. Bauer and Schiffinger [11] found that PD increases the effect of anticipated benefits on OSD.

P8a: Power distance increases the positive effect of anticipated benefits on OSD. 
P8b: Power distance moderates the effect of privacy concerns on OSD.

P8c: Power distance moderates the effect of trusting beliefs on OSD.

Uncertainty avoidance (UA) refers to a culture's attitude towards ambiguous and risky situations and whether it tries to avoid them. High levels thereof consequently imply greater concern, anxiety and stress. According to Bauer and Schiffinger [11], UA is among the two most influential cultural dimensions with respect to OSD (the other one being indulgence).

Our first proposition concerning UA (P9a) relates to its mitigating effect of anticipated benefits on OSD, which appears intuitive by nature and was also proven in earlier research [11].

P9a: Uncertainty avoidance decreases the positive effect of anticipated benefits on OSD.

Lim, et al. [45] posit that trust is strongly impacted by levels of both IDV and UA. The latter is assumed to be affected by pessimistic attitudes towards companies' incentives. Cultures with lower levels of UA tend to be less concerned about their privacy and are thus more likely to take risky actions on the basis of trust [24].

P9b: Uncertainty avoidance increases the positive effect of trusting beliefs.

Also, several studies have pointed out that higher levels of UA tend to lead to greater privacy concerns $[12,52,53]$. These findings emphasize the general concern that lies in the nature of cultures with high levels of UA.

P9c: Uncertainty avoidance increases the effect of privacy concerns on OSD.

The masculinity/femininity dimension (MAS) deals with gender roles and refers to whether a culture is more masculine or feminine. Masculinity is associated with men's assertiveness, materialism, success, less concern about others, and a stronger contrast to women's more gentle characteristics [32]. Femininity, on the other side of the continuum, describes cultures where both men and women tend to be rather tender, modest and concerned with quality of life [33].

MAS has also been examined in the context of privacy concerns: Milberg, et al. [53] have found a positive link between masculinity and privacy concerns. They concluded that stronger competitiveness leads to greater alert about misuse of PI. Krasnova and Veltri [42] came to a similar conclusion. Taking these findings into consideration, the following assumptions can be made:
P10a: Masculinity increases the negative effect of privacy concerns on OSD.

P10b: Masculinity increases the negative effect of risk beliefs on OSD.

The abovementioned reasoning by Krasnova and Veltri [42] and the underlying argument by Acquisti [1] concluding that striving for immediate benefits leads to higher OSD can also be used for explaining the effect of long-term orientation (LTO) on OSD: LTO might reinforce the effect of anticipated benefits on OSD. Although such an effect could not be shown in the study by Bauer and Schiffinger [11], we still postulate P11a, assuming a reinforcement of the positive effect. Furthermore, for the same reasoning by Krasnova and Veltri [42] and Acquisti [1], we expect that LTO augments the negative effects of privacy concern and of risk assessment on OSD; both impacts were shown in the study of Bauer and Schiffinger [11].

P11a: Long-term orientation decreases the positive effect of anticipated benefits on OSD.

P11b: Long-term orientation increases the negative effect of privacy concern on OSD.

P11c: Long-term orientation increases the negative effect of risk beliefs on OSD.

Bauer and Schiffinger [11] found in their analysis several moderating influences of indulgence on the privacy calculus theory predictors' effects on OSD. Their rather speculative line of argument states that indulgence also represents "control over one's life" [70], which explains their findings that indulgence reduces the positive effect of anticipated benefits (P12a), and tht it intensifies the negative effect of privacy concerns (P12b) and risk beliefs (P12c). Further research is necessary; for this reason, we include it in our open model of cultural OSD research.

P12a: Indulgence decreases the positive effect of anticipated benefits on OSD.

P12b: Indulgence increases the negative effect of privacy concerns on OSD.

P12c: Indulgence increases the negative effect of risk beliefs on OSD.

Figure 1 provides a synopsis of the above-described impacts of the predictors on OSD, together with the moderating effects of cultural dimensions. Positive and negative influences are visualized by arrows, which are tagged with the number of the respective proposition.

As shown in Figure 1, the relation of privacy concerns and OSD is influenced by the entire set of cultural dimensions, and the predictor anticipated benefits is also influenced by most of the moderators (except MAS). In the model, the relation between perceived anonymity and OSD is not influenced by any 
of the cultural attributes. Note that the relations depicted in Figure 1 are built on existing theories and/or results of empirical studies. Therefore, it shall not be concluded that there is no impact between a certain moderator and the relation between a certain predictor and OSD; it can only be concluded that (so far) there is no evidence for such an effect.

\section{Discussion and Conclusion}

PI disclosed by consumers online is a highly valuable source to learn about them. Not to mention, many online platforms would not even exist without the content provided by their users (i.e. user-generated content), including posts, comments, photos, and/or videos. As providers of such services largely rely on users' OSD, it is crucial for such organizations to study and understand users' OSD. For users, yet, it is not always favorable to provide their PI openly due to, among others, privacy and security reasons.

While organizations tend to consider a "culturally universal Internet user", we emphasize that, with respect to OSD, cultural uniformity does not exist. Consequently, organizations need to address their stakeholders differently across countries to be capable of handling their PI accordingly. This implies separate analysis of PI data across various countries and requires organizations to interact with users differently as users' OSD is affected by their culture.

Our open research model represents a comprehensive approach that provides a basis to perform cultural OSD research and to explain possible cultural OSD phenomena in a systematic way. It is built on several sub-approaches, which we have consolidated. These sub-approaches have proven to be reasonable in well-defined settings; furthermore, it incorporates novel aspects together with new causeand-effect chains largely underpinned by recent research. Our suggested open research model is propositions-driven and incorporates six moderators that affect the relation of six predictors on OSD. Thus, we suggest and substantiate 24 structured propositions. As it is an open model, it can be further developed and extended in continuous research endeavors.

The suggested propositions may be examined through laboratory experiments, survey studies, and/or field experiments. The sample population and their cultural background deserve careful choice and design so that conclusions can be generalized.

Further research on the cultural role in OSD may be performed in three major directions, i.e. method, provision of evidence, and applications.

Future method-oriented work may be twofold: focusing on $(i)$ the predictors and (ii) the moderators. Our model is based on the assumption that the suggested predictors are independent from each other and that they have no mutual effects or interdependencies; this needs to be substantiated by further empirical research. Another predictor-relevant research question refers to the completeness of the number of suggested predictors. Additional predictors should be incorporated into the model if further empirical studies introduce them; their independence of every other predictor in the model should be examined.

Further method-oriented work refers to the moderators: we have chosen Hofstede's work on cultural attributes because his studies provide up-todate numerical evidence that may be highly suitable to make transparent cultural distinctions in a certain context. Hofstede's approach has been criticized regarding conception, methodology, and interpretation [36,50]; for instance, for equating culture with nation and for disregarding ethnic aspects. Still, this approach seems to be appropriate for the purpose of business applications as companies usually target markets on a national or supranational level. Applying any other moderators' scheme is generally possible, but implies a re-evaluation of impacts (i.e. what effects are to be expected on which predictor-OSD-relation). With respect to the framework of contextual integrity that allows for defining norms on various group levels, this seems a promising perspective that we intend to pick up.

The second major direction of further work refers to the provision of evidence through empirical studies. Rather than performing research on a single country or making pairwise comparisons using one or two moderators, broader studies (in terms of cultures and/or of Hofstede's attributes) will lead to better quality in results and are to be preferred.

The third major direction of further work refers to applications, as our model has several benefits for the industry: for instance, companies that intend to launch marketing campaigns or products that are based on OSD or involve OSD (e.g. SNS applications) in new markets may perform an analysis to get well-founded insights into specific cultural attitudes of future customers. Future work should come up with frameworks and guidelines to support organizations in their international business activities.

Since concerns act as a barrier to protect users from disclosing too much PI and since users' tendencies to disclose PI are further tied to their cultural background, organizations need to include varying measures and actions depending on their users' native countries. Similarly, PI disclosed by users from different countries will require different measures for and degrees of data protection, since, depending on the 
cultural background, a user is more or less inclined to disclose PI in detail.

\section{Acknowledgments}

This research is supported by the Austrian Science Fund (FWF): V579.

\section{References}

[1] Acquisti, A., "Privacy in Electronic Commerce and the Economics of Immediate Gratification", ACM Electronic Commerce Conference (ACM EC 2004), 2004, pp. 21-29.

[2] Acquisti, A., L. Brandimarte, and G. Loewenstein, "Privacy and Human Behavior in the Age of Information", Science, 347(6221), 2015, pp. 509-514.

[3] Adomavicius, G., and A. Tuzhilin, "Toward the Next Generation of Recommender Systems: A Survey of the Stateof-the-Art and Possible Extensions", IEEE Transactions on Knowledge and Data Engineering, 17(6), 2005, pp. 734-749.

[4] Al-Saggaf, Y., and S. Nielsen, "Self-Disclosure on Facebook among Female Users and Its Relationship to Feelings of Loneliness", Computers in Human Behavior, 36, 2014, pp. 460-468.

[5] Altman, I., and D.A. Taylor, Social Penetration: The Development of Interpersonal Relationships, Holt, Rinehart and Winston, New York, NY, 1973.

[6] Ang, L., and B.-C. Lee, "Influencing Perceptions of Trustworthiness in Internet Commerce: A Rational Choice Framework", 5th CollECTer Conference on Electronic Commerce, 2000.

[7] Barak, A., and O. Gluck-Ofri, "Degree and Reciprocity of Self-Disclosure in Online Forums", Cyberpsychology \& Behavior, 10(3), 2007, pp. 407-417.

[8] Bauer, C., "Taking Responsibility for Online SelfDisclosure: The Thin Line between a Company's User Orientation and User Surveillance", GRES-IT Workshop Proceedings. Working Papers on Information Systems, Information Business and Operations, 02/2016, 2016, pp. 1718.

[9] Bauer, C., and P. Lasinger, "Adaptation Strategies to Increase Advertisement Effectiveness in Digital Media", Management Review Quarterly, 64(2), 2014,pp. 101-124.

[10] Bauer, C., and M. Schiffinger, "Self-Disclosure in Online Interaction: A Meta-Analysis", 48th Hawaii International Conference on System Sciences (HICSS 2015), 2015, pp. 3621-3630.

[11] Bauer, C., and M. Schiffinger, "Perceived Risks and Benefits of Online Self-Disclosure: Affected by Culture? A Meta-Analysis of Cultural Differences as Moderators of Privacy Calculus in Person-to-Crowd Settings", 24th European Conference on Information Systems (ECIS 2016), 2016.
[12] Bellman, S., E.J. Johnson, S.J. Kobrin, and G.L. Lohse, "International Differences in Information Privacy Concerns: A Global Survey of Consumers", Information Society, 20(5), 2004, pp. 313-324.

[13] boyd, d., "Why Youth (Heart) Social Network Sites: The Role of Networked Publics in Teenage Social Life", in Buckingham, D., (ed.): Youth, Identify, and Digital Media, MIT Press, Cambridge, MA, 2007, pp. 119-142.

[14] Burke, L., and J.M. Logsdon, "How Corporate Social Responsibility Pays Off", Long Range Planning, 29(4), 1996, pp. 495-502.

[15] Cao, J., and A. Everard, "User Attitude Towards Instant Messaging: The Effect of Espoused National Cultural Values on Awareness and Privacy", Journal of Global Information Technology Management, 11(2), 2008, pp. 30-57.

[16] Chapman, C.N., and M. Lahav, "International Ethnographic Observation of Social Networking Sites", CHI '08 Extended Abstracts on Human Factors in Computing System (CHI EA '08), 2008, pp. 3123-3128.

[17] Chelune, J.G., "Measuring Openness in Interpersonal Communication", in Chelune, J.G., (ed.): Selfdisclosure: Origins, Patterns and Implications of Openness in Interpersonal Relationship, Jossy-Bass, San Francisco, CA, 1979, pp. 14-30.

[18] Chen, R., and S.K. Sharma, "Self-Disclosure at Social Networking Sites: An Exploration through Relational Capitals", Information Systems Frontiers, 15(2), 2013, pp. 269-278.

[19] Cho, H., M. Rivera-Sánchez, and S.S. Lim, "A Multinational Study on Online Privacy: Global Concerns and Local Responses", New Media \& Society, 11(3), 2009, pp. 395-416.

[20] Connolly, T., L.M. Jessup, and J.S. Valacich, "Effects of Anonymity and Evaluative Tone on Idea Generation in Computer-Mediated Groups", Management Science, 36(6), 1990, pp. 689-703.

[21] Daley, A., "Being Recognized, Accepted, and Affirmed: Self-Disclosure of Lesbian/Queer Sexuality within Psychiatric and Mental Health Service Settings", Social Work Mental Health, 8(4), 2010, pp. 336-355.

[22] Dinev, T., M. Bellotto, P. Hart, V. Russo, I. Serra, and C. Colautti, "Privacy Calculus Model in E-Commerce: A Study of Italy and the United States", European Journal of Information Systems, 15(4), 2006, pp. 389-402.

[23] Dinev, T., and P. Hart, "An Extended Privacy Calculus Model for E-Commerce Transactions", Information Systems Research, 17(1), 2006, pp. 61-80.

[24] Doney, P.M., J.P. Cannon, and M.R. Mullen, "Understanding the Influence of National Culture on the Development of Trust", Academy of Management Review, 23(3), 1998, pp. 601-620.

[25] Ellison, N.B., C. Steinfield, and C. Lampe, "The Benefits of Facebook "Friends": Social Capital and College 
Students' Use of Online Social Network Sites", Journal of Computer-Mediated Communication, 12(4), 2007, pp. 11431168 .

[26] Floridi, L., "Four Challenges for a Theory of Informational Privacy", Ethics and Information Technology, 8(3), 2006, pp. 109-119.

[27] Fogel, J., and E. Nehmad, "Internet Social Network Communities: Risk Taking, Trust, and Privacy Concerns", Computers in Human Behavior, 25(1), 2009, pp. 153-160.

[28] Galegher, J., L. Sproull, and S. Kiesler, "Legitimacy, Authority, and Community in Electronic Support Groups", Written Communication, 15(4), 1998, pp. 493-530.

[29] Gefen, D., V.S. Rao, and N. Tractinsky, "The Conceptualization of Trust, Risk and Their Electronic Commerce: The Need for Clarifications", 36th Hawaii International Conference on System Sciences (HICSS 2003), 2003.

[30] Greenfield, P., "Three Approaches to the Psychology of Culture: Where Do They Come From? Where Can They Go?", Asian Journal of Social Psychology, 3(3), 2000, pp. 223-240.

[31] Gupta, B., L.S. Iyer, and R.S. Weisskirch, "Facilitating Global E-Commerce: A Comparison of Consumers' Willingness to Disclose Personal Information Online in the U.S. And India", Journal of Electronic Commerce Research, 11(1), 2010, pp. 41-52.

[32] Hofstede, G., Culture's Consequences: Comparing Values, Behaviors, Institutions, and Organizations across Nations, Sage, Thousand Oaks, 2001.

[33] Hofstede, G., G.J. Hofstede, and M. Minkov, Cultures and Organizations: Software of the Mind, McGraw-Hill, Revised and expanded 3rd edn, New York, NY, 2010.

[34] Joinson, A.N., C. Paine, T. Buchanan, and U.-D. Reips, "Measuring Self-Disclosure Online: Blurring and NonResponse to Sensitive Items in Web-Based Surveys", Computers in Human Behavior, 24(5), 2008, pp. 2158-2171.

[35] Joinson, A.N., U.-D. Reips, T. Buchanan, and C.B.P. Schofield, "Privacy, Trust, and Self-Disclosure Online", Human-Computer Interaction, 25(1), 2010, pp. 1-24.

[36] Jones, M.L., "Hofstede - Culturally Questionable?", Oxford Business \& Economics Conference, 2007.

[37] Jourard, S.M., and P. Lasakow, "Some Factors in SelfDisclosure", Journal of Abnormal and Social Psychology, 56(1), 1958, pp. 91-98.

[38] Kankanhalli, A., B.C.Y. Tan, and K.K. Wei, "Contributing Knowledge to Electronic Knowledge Repositories: An Empirical Investigation", MIS Quarterly, 29(1), 2005, pp. 113-143.

[39] Kisekka, V., S. Bagchi-Sen, and H.R. Rao, "Extent of of Private Information Disclosure on Online Social Networks: An Exploration of Facebook Mobile Phone Users", Computers in Human Behavior, 29(6), 2013, pp. 2722-2729.
[40] Kisilevich, S., C.S. Ang, and M. Last, "Large-Scale Analysis of Self-Disclosure Patterns among Online Social Networks Users: A Russian Context", Knowledge and Information Systems, 32(3), 2012, pp. 609-628.

[41] Krasnova, H., and N.F. Veltri, "Privacy Calculus on Social Networking Sites: Explorative Evidence from Germany and USA", 43rd Hawaii International Conference on System Sciences (HICSS 2010), 2010, pp. 1-10.

[42] Krasnova, H., and N.F. Veltri, "Behind the Curtains of Privacy Calculus on Social Networking Sites: The Study of Germany and the USA", 10. Internationale Tagung Wirtschaftsinformatik (Wirtschaftsinformatik 2011), 2011.

[43] Krasnova, H., N.F. Veltri, and O. Günther, "SelfDisclosure and Privacy Calculus on Social Networking Sites: The Role of Culture: Intercultural Dynamics of Privacy Calculus", Business \& Information Systems Engineering, 4(3), 2012, pp. 127-135.

[44] Lee, J.N., "The Impact of Knowledge Sharing, Organizational Capability and Partnership Quality on Is Outsourcing Success", Information \& Management, 38(5), 2001, pp. 323-335.

[45] Lim, K.H., K. Leung, C.L. Sia, and M.K. Lee, "Is Ecommerce Boundary-Less? Effects of IndividualismCollectivism and Uncertainty Avoidance on Internet Shopping", Journal of International Business Studies, 35(6), 2004, pp. 545-559.

[46] Liu, C., R.P. Ang, and M.O. Lwin, "Cognitive, Personality, and Social Factors Associated with Adolescents' Online Personal Information Disclosure", Journal of Adolescence, 36(4), 2013, pp. 629-638.

[47] Liu, C., J.T. Marchewka, and C. Ku, "American and Taiwanese Perceptions Concerning Privacy, Trust, and Behavioral Intentions in Electronic Commerce", Journal of Global Information Management, 12(1), 2004, pp. 18-40.

[48] McKenna, K.Y.A., and J.A. Bargh, "Coming out in the Age of the Internet: Identity "Demarginalization" through Virtual Group Participation", Journal of Personality and Social Psychology, 75(3), 1998, pp. 681-694.

[49] McKenna, K.Y.A., and J.A. Bargh, "Plan 9 from Cyberspace: The Implications of the Internet for Personality and Social Psychology", Personality and Social Psychology Review, 4(1), 2000, pp. 57-75.

[50] McSweeney, B., "Hofstede's Model of National Cultural Differences and Their Consequences: A Triumph of Faith - a Failure of Analysis", Human Relations, 55(1), 2002, pp. 89118.

[51] Metzger, M.J., "Privacy, Trust and Disclosure: Exploring Various Barriers of E-Commerce", Journal of Computer-Mediated Communication, 2004,

[52] Milberg, S.J., S.J. Burke, H.J. Smith, and E.A. Kallman, "Values, Personal Information Privacy, and Regulatory Approaches", Communications of the ACM, 38(12), 1995, pp. 65-74. 
[53] Milberg, S.J., H.J. Smith, and S.J. Burke, "Information Privacy: Corporate Management and National Regulation", Organization Science, 11(1), 2000, pp. 35-57.

[54] Moon, Y., "Intimate Exchanges: Using Computers to Elicit Self-Disclosure from Consumers", Journal of Consumer Research, 26(4), 2000, pp. 323-339.

[55] Mukherjee, S., J.A. Manjaly, and M. Nargundkar, "Money Makes You Reveal More: Consequences of Monetary Cues on Preferential Disclosure of Personal Information", Frontiers in Psychology, 4, 2013,pp. 839.

[56] Nissenbaum, H., "Privacy as Contextual Integrity", Washington Law Review, 79(1), 2004, pp. 119-157.

[57] Nissenbaum, H., Privacy in Context: Technology, Policy, and the Integrity of Social Life, Stanford University Press, Stanford, CA, 2009.

[58] Nosko, A., E. Wood, and S. Molema, "All About Me: Disclosure in Online Social Networking Profiles: The Case of Facebook", Computers in Human Behavior, 26(3), 2010, pp. 406-418.

[59] Nunamaker Jr., J.F., A. Dennis, J. Valacich, D. Vogel, and J. George, "Electronic Meeting Systems to Support Group Work", Communications of the ACM, 34(7), 1991, pp. 40-61.

[60] Pennebaker, J.W., "Confession, Inhibition, and Disease", in Berkowitz, L., (ed.): Advances in Experimental Social Psychology, Academic, New York, NY, 1989, pp. 211-244.

[61] Pfeil, U., P. Zaphiris, and C.S. Ang, "Cultural Differences in Collaborative Authoring of Wikipedia", Journal of Computer-Mediated Communication, 12(1), 2006, pp. 88-113.

[62] Posey, C., P.B. Lowry, T.L. Roberts, and T.S. Ellis, "Proposing the Online Community Self-Disclosure Model: The Case of Working Professionals in France and the U.K. Who Use Online Communities", European Journal of Information Systems, 19(2), 2010, pp. 181-195.

[63] "Regulation (Eu) 2016/679 of the European Parliament and of the Council of 27 April 2016 on the Protection of Natural Persons with Regard to the Processing of Personal Data and on the Free Movement of Such Data", 2016.

[64] Rosen, P., and P. Sherman, "Hedonic Information Systems: Acceptance of Social Networking Websites", Americas Conference on Information Systems (AMCIS 2006), 2006.

[65] Rubin, Z., "Friendship, Proximity, and Self-Disclosure", Journal of Personality, 46(1), 1978, pp. 1-22.

[66] Schouten, A.P., P.M. Valkenburg, and J. Peter, "Precursors and Underlying Processes of Adolescents' Online Self-Disclosure: Developing and Testing an "InternetAttribute-Perception" Model", Media Psychology, 10(2), 2007, pp. 292-315.

[67] Shibchurn, J., and V. Xiang Bin, "Investigating Effects of Monetary Reward on Information Disclosure by Online
Social Networks Users", 47th Hawaii International Conference on System Sciences (HICSS 2014), 2014, pp. 1725-1734.

[68] Singh, T., and M.E. Hill, "Consumer Privacy and the Internet in Europe: A View from Germany", Journal of Consumer Marketing, 20(7), 2003, pp. 634-651.

[69] Sledgianowski, D., and S. Kulviwat, "Social Network Sites: Antecedents of User Adoption and Usage", Americas Conference on Information Systems (AMCIS 2008), 2008.

[70] Smith, P.B., "Communication Styles as Dimensions of National Culture", Journal of Cross-Cultural Psychology, 42(2), 2011, pp. 216-233.

[71] Staples, D.S., and J. Webster, "Exploring the Effects of Trust, Task Interdependence and Virtualness on Knowledge Sharing in Teams", Information Systems Journal, 18(6), 2008, pp. 617-640.

[72] Suler, J., "The Online Disinhibition Effect", Cyberpsychology \& Behavior, 7(3), 2004, pp. 321-326.

[73] Trepte, S., and L. Reinecke, "The Effects of Social Network Use on Privacy, Social Support, and Well-Being: A Longitudinal Study", 3rd European Communication Conference (ECREA 2010), 2010.

[74] Triandis, H.C., and E.M. Suh, "Cultural Influences on Personality", Annual Review of Psychology, 53(1), 2002, pp. 133-160.

[75] Tsikriktsis, N., "Does Culture Influence Web Site Quality Expectations?", Journal of Service Research, 5(2), 2002, pp. 101-112.

[76] Tufekci, Z., "Can You See Me Now? Audience and Disclosure Regulation in Online Social Network Sites", Bulletin of Science, Technology \& Society, 28(1), 2008, pp. 20-36.

[77] Veltri, N.F., H. Krasnova, and W. Elgarah, "Online Disclosure and Privacy Concerns: A Study of Moroccan and American Facebook Users", American Conference on Information Systems (AMCIS 2011), 2011.

[78] Wakefield, R., "The Influence of User Affect in Online Information Disclosure", Journal of Strategic Information Systems, 22(2), 2013, pp. 157-174.

[79] Xu, X., T. Dinev, H.J. Smith, and P. Hart, "Examining the Formation of Individual's Privacy Concerns: Toward an Integrative View", International Conference on Information Sytems (ICIS 2008), 2008.

[80] Zhao, C., P. Hinds, and G. Gao, "How and to Whom People Share: The Role of Culture in Self-Disclosure in Online Communities", ACM Conference on ComputerSupported Cooperative Work and Social Computing (CSCW 2012), 2012, pp. 67-76.

[81] Zimmer, J.C., R.E. Arsal, M. Al-Marzouq, and V. Grover, "Investigating Online Information Disclosure: Effects of Information Relevance, Trust and Risk", Information \& Management, 47(2), 2010, pp. 115-123. 